\title{
DASY BASED TOOL FOR THE DESIGN OF ICE MECHANISMS
}

\section{RADEK TICHÁNEK}

CTU in Prague, Faculty of Mechanical Engineering; Technická 4, Praha 6, 166 07, Czech Republic, Tel: +420224352507

Email: radek.tichanek@fs.cvut.cz

\section{SHRNUTÍ}

Článek prezentuje nástroj pro navrhování nových mechanismů spalovacího motoru založený na znalostní databázi DASY.Z mechanismů motoru byl vybrán rozvodový mechanismus $\mathrm{OHC}$ na kterém byl nástroj vyvinut a testován. Nástroj obsahuje kinematický a dynamický model rozvodu napojený na klikový mechanismus. Podrobnou kalibrací a následnou validací třech dynamických modelů s měřenými daty, byly získány hodnoty neznámých parametrů modelů, které jsou zaznamenány v DASY a mnohé parametry jsou prímo použitelné pro návrh nového mechanismu i při změně geometrie některých částí. $V$ článku jsou prezentovány tř̌i postupy použité nejen pro kalibraci, ale také pro identifikaci vlivu neznámých parametrů na průběh zrychlení ventilu a jeho kmitání. Nástroj byl použit pro návrhy obrysů vaček pro prototyp reálného mechanismu.

KLIĆOVÁ SLOVA: DASY, SYSTÉM PODPORY NÁVRHU, VENTILOVÝ ROZVOD, KLIKOVÝ MECHANISMUS, ZRYCHLENÍ VENTILU, OPTIMALIZACE, MECHANISMY SPALOVACÍHO MOTORU

\section{ABSTRACT}

This article presents a tool for designing new mechanisms of internal combustion engines based on the DASY knowledge database. An $\mathrm{OHC}$ valve train has been chosen for developing and testing the presented tool. The tool includes both a kinematic and dynamic model connected to a crank train. Values of unknown parameters have been obtained using detailed calibration and consequent validation of three dynamic models with measured data. The values remain stored in DASY and many of them can be used directly to design new mechanisms, even in cases where the geometries of some parts are different. The paper presents three methods which have been used not only for the calibration, but also for the identification of the influence of unknown parameters on valve acceleration and its vibration. The tool has been used to design the cam shapes for a prototype of the new mechanism.

KEYWORDS: DASY, DESIGN ASSISTANCE SYSTEM, VALVE TRAIN, CRANK TRAIN, VALVE ACCELERATION, OPTIMIZATION, ICE MECHANISMS

\section{INTRODUCTION}

Work by specialists on developing one of the systems of an IC engine, or part thereof, combines many processes, beginning with setting goals, continuing with the prototype design phase, which is supported with calculations, its production, and ends with an evaluation of the final prototype tests. Processes involve different areas of research, particularly thermodynamics, mechanics, engine control and more for IC engines. In the design phase some simulation models are applied that allow the behavior of the proposed systems to be predicted. Measurement on real systems is still the key for building simulation models. Measurement enables the first validation of simulation models of the actual systems, it helps in detecting unknown systems parameters and also, where appropriate, their dependence on input variables, for example on the engine speed. These parameters and dependencies can be applied in the simulation models of the proposed systems, which are similar in their structure and differ for example only in the dimensions of certain parts, thereby increasing the accuracy of the models and the range of their applicability.

If we limit our further considerations to mechanical systems, the unknown parameters are, for example, properties of contacts between metal parts. There are some recommended values for them, but these often do not meet all the solved cases, and it is necessary to find satisfactory values for the solved case. One of the examined mechanisms is an $\mathrm{OHC}$ valve train with hydraulic lash adjuster. In this case several contact pairs are solved, whose 
parameters have a significant influence on the results of the simulation model. The measured signal provides true information about the absolute values of measured quantities, further FFT analysis of the signal will provide, for example, the characteristics of vibration, size of amplitudes and their frequencies. However, the influence of these parameters and their dependencies are encoded in the measured signals and individual parameters may have different but also a similar influence on the course of the signal. Therefore, the measurement itself is not enough to determine the influence of the unknown parameters. There is another area that offers the usage of simulation models, which may be used for identifying the influences of parameters that most affect the measured signal.

Compliance of measured characteristics with calculated characteristics at a certain RPM is a criterion for finding the values of the unknown parameters. Compliance of the characteristics throughout selected RPM speed range is a criterion for finding dependencies of the unknown parameters values on RPM.

Three methods are used to find the values of the unknown parameters in this work. The first method is a what-if study of the influence of changes in the values of the parameters on the monitored characteristic that is obtained calculating the DoE. The value of one parameter is always changed within one set of DoE. A better understanding of the impact results from the subsequent evaluation of the $D o E$, in which the amount of influence that the change in the value of a particular parameter has on the monitored characteristic is evaluated. More generally, the DoE is used here as a method for seeking the parameters with the largest impact on the observed characteristic and the possibility of affecting it.

The second method is searching the values of the parameters using a multi-objective genetic optimization algorithm. This algorithm is robust and proven in the search of the final parameter values. Due to the time-consuming nature of the algorithm it is necessary to limit the group of variables entered into the algorithm. This can be successfully done using a DoE method, which looks for parameters with the greatest influence, and they are then the input variables in the algorithm.

The third method is using simulation models of varying complexity. The unknown parameters of the model are easier to look for in the genetic algorithm in a simple model because there are not many of them. More complex elements are then added to the model, thus gathering knowledge about the influence that the elements and its parameters have on the progress of the quantities that are compared with measurements. A valve spring based on finite element formulation and a hydraulic lash adjuster are the elements that were gradually added into the mechanical model in the case of the simulation of the dynamic behavior of valve mechanism. The effect of adding these elements was analyzed in an acceleration course of the valve.
The validated model of the real mechanism is the default model for the settings of the simulation model of the mechanism, which is in the design phase. The found values of the parameters obtained in the validation of the model described by the methods are taken via the DASY model into the simulation model of the proposed mechanism. This model is then used for the calculations which predict the dynamic behavior of the valve train when changing parts, typically when changing the valve lift curves. The subsequent calculation of a cam shape is used as the basis for preparing a new prototype of a camshaft.

\section{DESCRIPTION OF THE SIMULATION MODELS}

A kinematic model reflects the geometry of the proposed mechanism. There are no unknown parameters in a kinematical simulation model. The required cylinder charge exchange determines the design and geometry of the mechanism. A thermodynamic model of the engine simulates cylinder charge exchange, the optimal parameters of the valve lift curve are sought for the required cylinder charge exchange in this model. Linking the thermodynamic engine model with the mechanical one makes it easier to find the optimal parameters for the valve lift curve because the mechanical model provides constraints for optimization. These constraints are the functionality, durability, manufacturability etc. of the mechanism. The limiting parameter for the optimization in the case of the cam shape is the size of the maximum negative value of its radius of curvature, which is limited by the radius of the grinding tool used to produce the cam shape.

The principle of the cam shape optimization is shown in Figure 1. The optimization loop begins the interpolation of the valve lift curve calculated for the optimal cylinder charge exchange.

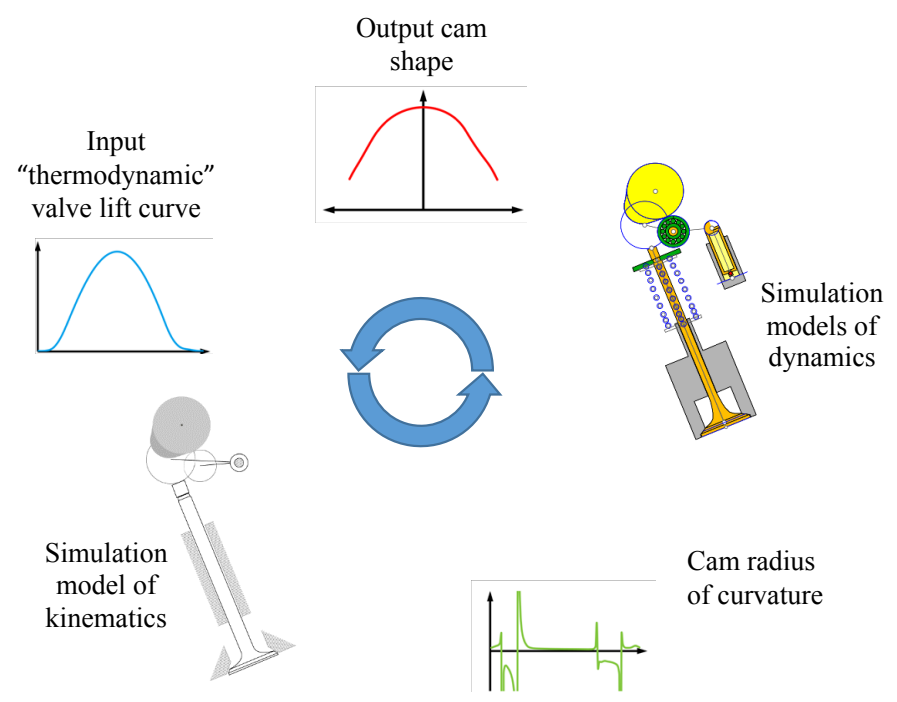

FIGURE 1: Optimization diagram.

OBRÁZEK 1: Schéma postupu optimalizace. 
The contour of the cam is calculated in the kinematic model and the maximum negative radius of curvature is checked there. The cam contour is checked in a dynamic model of the mechanism which is used to predict deviations from the kinematic valve lift curve, which is caused by the flexibility of the valve train. VT-DESIGN is used for kinematic analysis. A computer-aided environment GT Suite is used for the simulation of valve train dynamics (Gamma Technologies).

Three dynamic models were used to determine the dynamic behavior of the valve train components. The models differ in the complexity of characteristic elements.

The "simple" model is the simplest variant of the $\mathrm{OHC}$ mechanism. The model contains a variety of components which will later be described in more detail. The valve spring (position 1 in Figure 2 a.) is a completely linear lumped-element model of a cylindrical spring. Its coils have been modeled as a number of masses connected with springs and dampers. The number of masses per coil determines the number of degrees of freedom to be used in the spring model. One mass per coil has been used in the model. Inter-coil contacts are disabled and, thus this type of spring model is not recommended for analyzing spring surge. Additionally, this model could not be used for modeling the progressive rate of the spring.

A model for calculating a contact force has been applied when a valve contacts a seat (position 2 in Figure 2 a.). The contact is modeled as a mass-less spring, whose parameters are stiffness and damping. Contact forces are normally applied to a contact line represented via a valve seat geometry. The stiffness is applied in a contact layer throughout which it increases through a smooth curve from zero, at the beginning of the layer, to the specified value of contact stiffness. The damping is associated with contact between the two parts and the damping force is applied whenever the parts are moving towards each other and a contact gap between them is lower than the specified value. The value of the contact gap specifies a layer where the damping force is applied on each of the parts even before they physically contact each other. This attribute can be used to model an oil film thickness present between the parts.

A valve (position 3 in Figure 2 a.) has been modeled by a threemass elastic system. The total mass of the valve is divided up among three masses of a stem, a head and a head seat. These masses are connected by two springs, a stem spring and a head-seat spring. Total (overall) valve stiffness is specified as measured applying a tensile load to the tip of the stem with the seat fixed. The stem spring stiffness is calculated using the material properties and geometry. The head-seat spring stiffness has been calculated using a combination of springs in series from the total and stem stiffness, see [2] for details. A valve retainer connects the valve and the valve spring. The retainer (position 4 in Figure 2 a.) has been modeled as a single mass with rigid connection to the valve stem tip. The valve is joined to a valve guide by a prismatic joint (position 5 in Figure 2 a.) that enforces zero relative rotation between the connected parts and relative displacement along a given axis.

Guide friction has been calculated in this joint. Friction force is a load-dependent product of the guide side load, which arises due to force from a finger follower contact on the valve, and a friction coefficient. A contact element has been defined between the valve and the rocker arm (position 6 in Figure 2 a.). There is $2 \mathrm{D}$ contact based on geometrical information specified for each part in the kinematical model. The contact stiffness and damping is calculated from the specified geometry and the elastic-hydrodynamic properties of the contact. The full Hertz/ EHD/Greenwood-Tripp model is performed to calculate Hertz stress and deformation, hydrodynamic friction forces, wear load and its distribution, power dissipation and tribological quantities such as oil film thickness.

A discrete model has been used to simulate the motions, stiffness and damping of the end pivoted finger follower rocker (position 7 in Figure 2 a.). The model is divided into three nodes, a central cam contact node, an end pivot arm node and a valve contact arm node. Each node's inertia is defined as a fraction of the total inertia according to equations, see [2] for details. The stiffness in the finger follower is represented as two torsional springs between the central cam node and the arm of both the pivot and the valve. The total stiffness in the finger follower is represented as a linear term of force per unit deflection cam node in the direction perpendicular to the finger. The stiffness is measured applying a force on the cam contact perpendicular to the finger axis with simple supports at both the pivot and valve ends. The total stiffness is distributed above to each torsional spring by calculation of equations for lumped models.

The contact element with 2D socket geometry has been defined between the finger follower and its pivot (position 8 in Figure 2 a.). There is a "gothic arch" based socket which has a 3D ring contact with a mating sphere. Two points of contact between the socket and the sphere can be predicted in 2D which means that load distribution is unable to accurately predict the actual $3 \mathrm{D}$ ring full contact. This differs from other types of contact geometry where both a $2 \mathrm{D}$ and $3 \mathrm{D}$ model will predict the same contact points i.e. 3D sphere-to-sphere and 2D circle-to-circle will both predict an elliptical single-point contact. Hertzian contact theory only applies to point and line contacts, so there is no formal solution for applying this theory to a $3 \mathrm{D}$ ring-shaped contact area. For this reason, this type of contact is unable to predict contact stiffness and damping. The advantage of using the $2 \mathrm{D}$ socket geometry is that it more accurately captures the dynamics of this interface, it predicts the load vector between the sphere and socket and the stability of the sphere in the socket etc. 

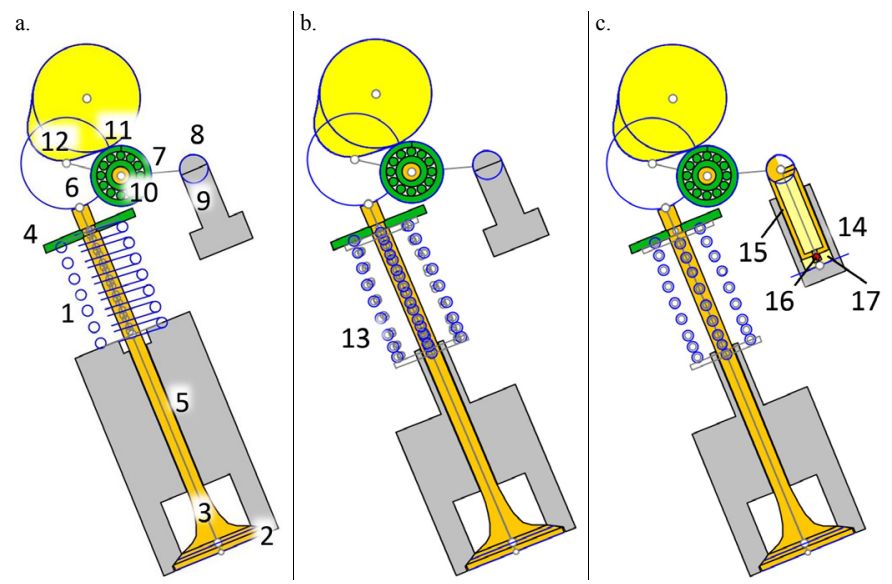

FIGURE 2: Simulation models of valve trains a. "simple", b. "simple_FE", c. "simple_FE_HLA"

OBRÁZEK 2: Simulační modely rozvodů a. "simple", b. "simple_FE", c. "simple_FE_HLA"

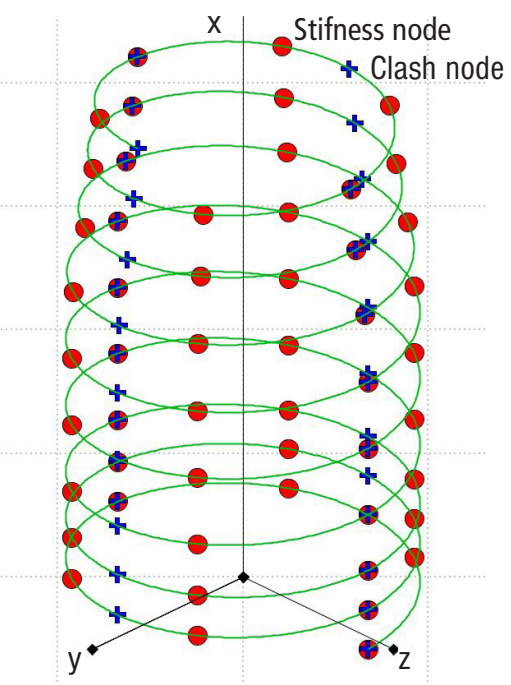

FIGURE 3: Diagram of FE spring.

OBRÁZEK 3: Schéma elementů pružiny.

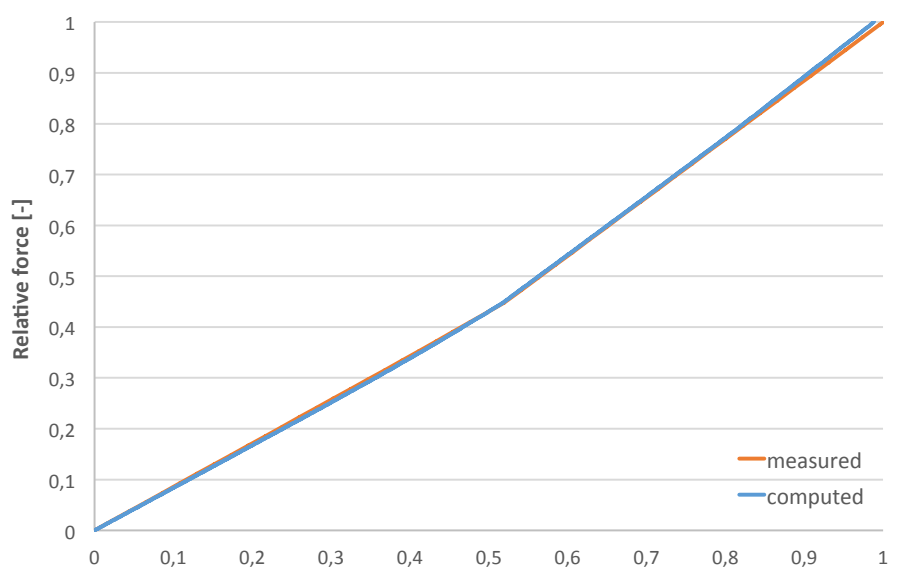

FIGURE 4: Static characteristic of FE spring. OBRÁZEK 4: Statické charakteristiky pružin.
A finger pivot has represented a rigid pivot (position 9 in Figure 2 a.), around which the finger follower rotates. The finger pivot has been connected to a ground.

A roller (position 10 in Figure 2 a.) connects the finger follower with a cam lobe. It is a simple rotating cylinder supported via a revolute joint to the finger follower. The revolute joint enforces zero relative displacements between these connected bodies at the connecting point. The model is able to calculate friction torque and friction power loss on the combined effects of dry and viscous friction. Those parameters have been neglected in this model. However, they are important for investigating the local effect of friction torque on the rotating roller.

The contact between the cam and the roller (position 11 in Figure $2 \mathrm{a}$.) is the most important place for the application of the full Hertz/EHD/Greenwood-Tripp. Contact geometry information is specified for each part of the kinematical model. The contact stiffness and damping are calculated from the specified geometry and elastic-hydrodynamic properties of the contact in the same way as in the case of the finger follower to the valve contact. The cam profile is defined at the cam lobe (position 12 in Figure 2 a.), the cam angle defining the start of the lift event. These attributes define the associated kinematical model. Lobe properties such as inertia, stiffness and damping are added in the dynamic model. The cam lobe is connected to a camshaft segment. A segment of the camshaft, between two journals belonging to one cylinder has been modeled, where both torsional and bending stiffness are considered. The valve train model has been attached to a model of a crank train which drives the camshaft. The crank train has been driven at a constant RPM. The crank train model is described in [1]. The valve train model shares with the crankshaft mechanism the kinematic model to investigate the collisions between a piston and the valves, an in-cylinder pressure profile which also acts on the valves. In the presented model, the in-cylinder pressure profile is neglected because the measurements for calibration of the valve train model have been done on a driven engine without combustion.

A "simple_FE" model differs from a "simple" model using a finite element valve spring model (position 13 in Figure 2 b.). Spring coils are represented using one-dimensional curved beam elements. By using finite-element techniques spring stiffness and mass are distributed continuously above a spring geometry. The spring geometry is conical with circular cross section of a wire. A conical shape is represented describing the mean coil diameter as a function of angle round the spring helix. An equivalent stiffness versus compression profile has been generated from measured force versus displacement data. Clash distances are calculated through interpolation. The spring FE model captures coils closure during compression events via the presence of coilto-coil contact forces which are distributed along the spring wire. This is maintained due to the definition of contact surfaces 


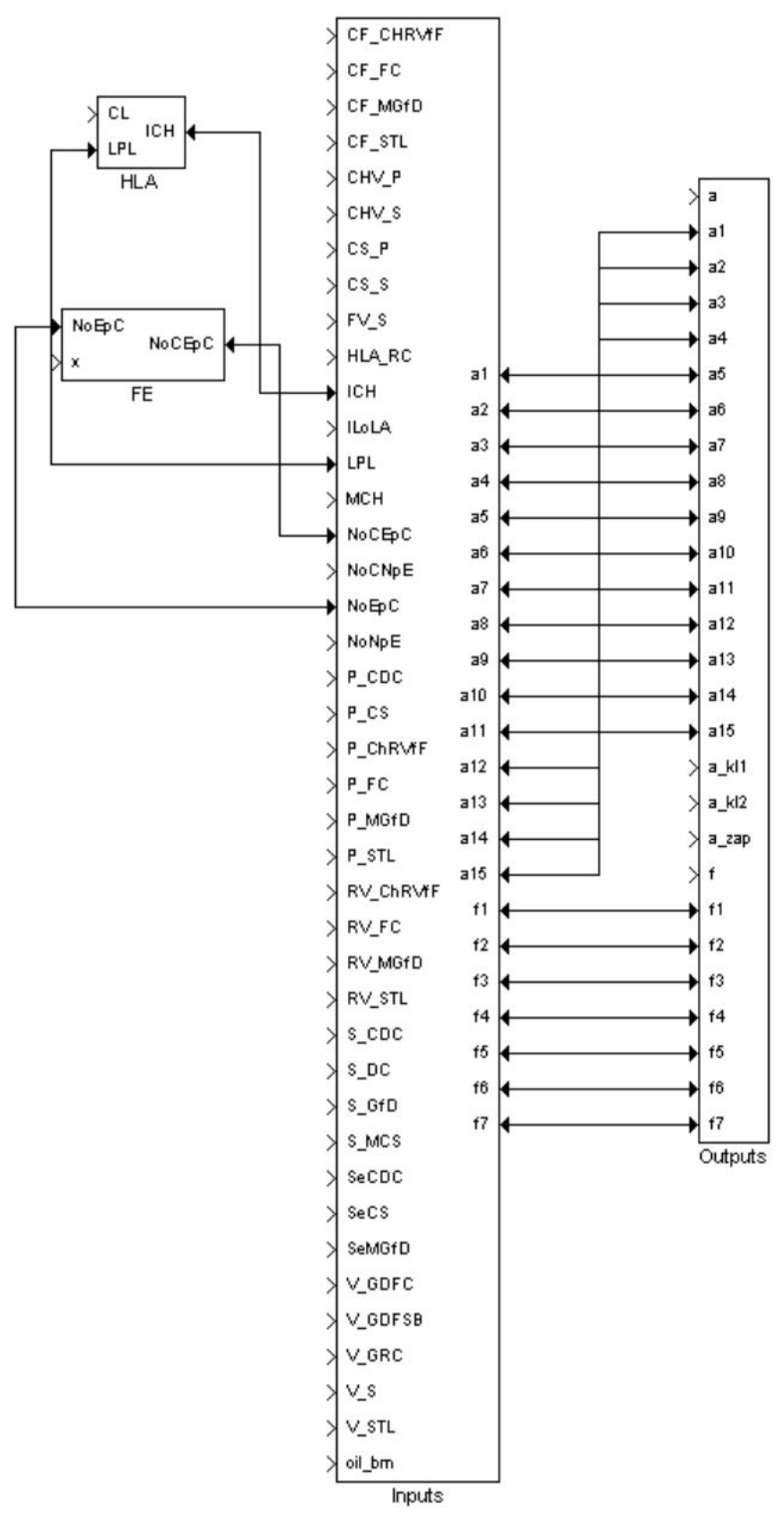

FIGURE 5: Block diagram of the DASY model for "simple_FE_HLA" valve train. OBRÁZEK 5: Blokové schéma modelu v DASY mechanismu "simple_FE_HLA".

which are modeled as spline shapes, given the Number of Clash Nodes per Element. Contacts are modeled continuously along two neighboring surfaces. Figure 3 shows a diagram of an FE spring with numbers and positions of stiffness and clash nodes. A static characteristic of the FE valve spring model has been compared with a measured one, see Figure 4. The FE spring model satisfactorily captures the non-linear static characteristic of the measured valve spring.

The "simple_FE_HLA" model is different from the "simple_FE" model in usage of a hydraulic lash adjuster pivot. The HLA pivot model contains five major components. There is a cylinder (position 14 in Figure $2 \mathrm{c}$.) that represents the housing of the $\mathrm{HLA}$, inside the chamber is a plunger (position 15 in Figure $2 \mathrm{c}$.), which contains a hollow through which the oil is pumped in from the oil gallery maintained at a constant pressure. Attached to the plunger is a check ball valve (position 16 in Figure 2 c.). The check valve controls the flow of oil from the oil gallery into the high pressure chamber (position 17 in Figure 2 c.). Equations from continuity, ideal gas, and compressibility [2] are combined together to form the final solution of the differential change in pressure with respect to time in the chamber of the hydraulic lash adjuster.

\section{IMPLEMENTATION OF MECHANICAL MODELS INTO DASY}

The Design Assistance System (DASY) features descriptive model definition, numerical solvers and optimization algorithms. Figure 5 shows the "simple_FE_HLA" model in DASY. The model is represented as a set of blocks linked with connections. Each block contains a set of equations, which are defining its sub-model. A sandbox approach is used for each block, which means that parameters used in equations of this block are accessible by this block only. A connection is used to connect the parameter of the first block with the parameter of the second block. The connection provides a bridge between two separate block sandboxes. The connected parameter values are assumed to be equal.

The "simple_FE_HLA" model in DASY is described via definition of input and output parameters separately from the model definition. This allows swapping of input and output parameters into and from the "simple_FE_HLA". The input parameters correspond with the variables described for each element of the mechanisms. The "Inputs" block contains these parameters on the left side, see Figure 5, and the outputs from the simulation connected with the "Outputs" block. This block contains additional relations to calculate the optimization objectives. The built-in solver in DASY using a genetic algorithm is an appropriate tool for solving optimizations. This solver has been used for finding the values of the unknown parameters. The targets of optimizations have always been minimizing standard deviations of outputs compared with measured data. Both the "HLA" block and "FE" block calculate dependent variables.

\section{CALIBRATION AND VALIDATION OF SIMULATION MODELS}

The accuracy of the kinematic model has been validated by comparing the acceleration of the valve, while one had been calculated from the known cam profile (computed) and the second had been known (original). The calculation procedure 


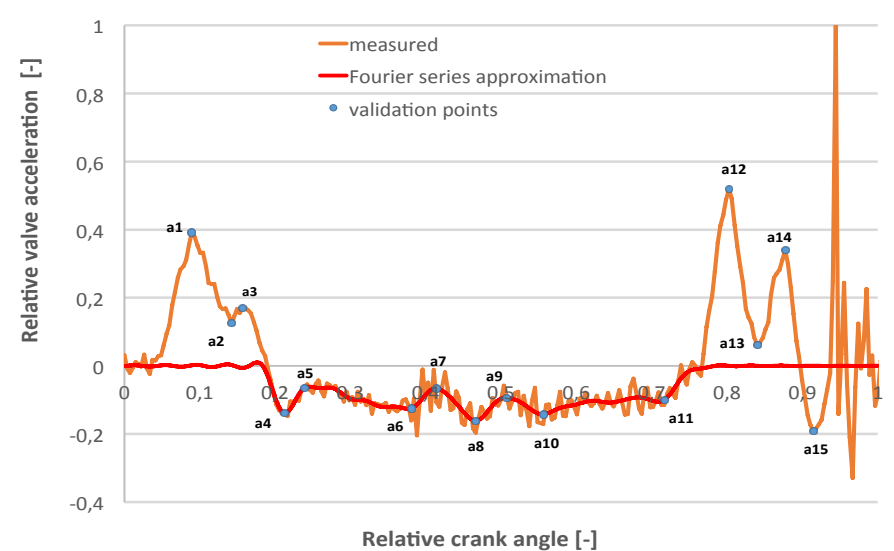

FIGURE 6: Selection of validation points for optimization models in measured profile of acceleration.

OBRÁZEK 6: Výběr bodů v měřeném průběhu pro optimalizaci modelů.

is as follows. The known cam profile is given $X, Y$ coordinates of the contour of the cam, from which the cam radius and its angle have been calculated. In general, the angle may not have a constant increment, but it is recommended to convert it on the constant increment because simple differential schemes for a numerical derivative are defined for the constant increment. Careful interpolating input data provide a smooth derivative, which is important for calculating dynamics, as the harmonic components of cam are an excitation in terms of the dynamics. The described procedure has verified the satisfactory accuracy of the kinematic model.

All dynamic models have been used to investigate the effect of selected parameters on a profile of the valve acceleration and the amplitudes of valve acceleration in frequency domain. The fifteen values on the valve acceleration profile have been chosen on a measured profile for comparing with the calculated one, see Figure 6 . The negative part of the measured profile has been approximated via 64 terms of the Fourier series for determining representative validation points.

The first main criterion of multi-objectives optimization has been to minimize the mean quadratic deviation of the calculated profile of valve acceleration from what has been measured. The mean quadratic deviation has been calculated from that selected point. The second main criterion chosen are seven values of amplitudes of acceleration, analyzed from the measured profile, for comparing with the calculated one in a frequency domain, see Figure 7 . This combination has proved to be useful because the optimization algorithm had sometimes found a satisfactory solution in terms of amplitudes of acceleration in a frequency domain but it had failed in the case of acceleration (fifteen values on profile). Alternatively, the user can select between these two criteria or can combine them with other pre-defined partial criteria such as a first peak, a negative part and a second peak of acceleration. The genetic

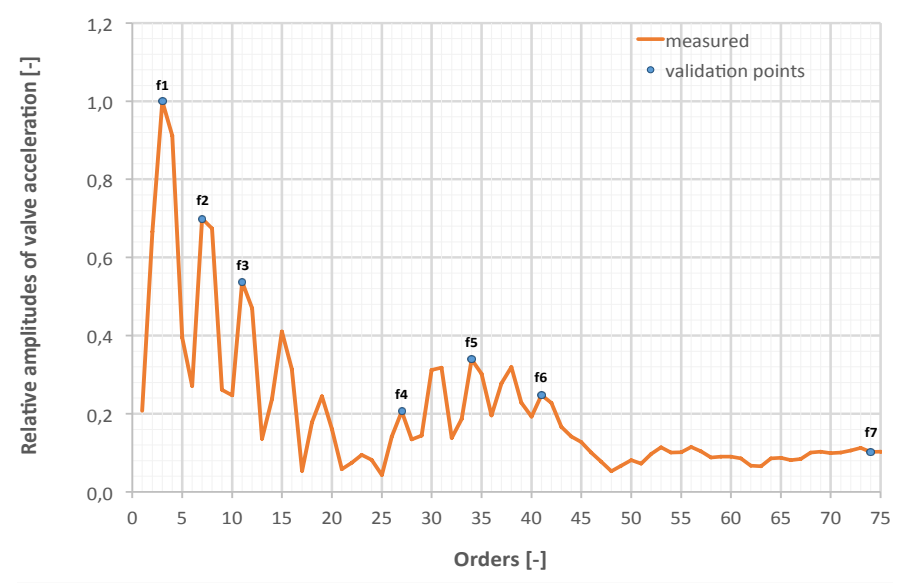

FIGURE 7: Selection of validation points for optimization in a frequency domain.

OBRÁZEK 7: Výběr bodů pro optimalizaci modelů ve frekvenční doméně.

algorithm has been looking for such values of variables to fulfill these objectives. Two main objectives have usually been chosen and the number of variables ranged between five and twenty.

\subsection{VALIDATION OF "SIIMPLE" MODEL.}

The "simple" model has been used to validate the influence of those parameters which were expected to have little influence on the results. These parameters remain at constant values in the "simple_FE" and "simple_FE_HLA" models. A list of parameters contains the contact parameters such as thickness of stiffness transition layers, maximum gaps for damping and parameters of friction in positions $6,8,11$, see Figure 2 . Values of damping coefficient and stiffness in position 8 had not been predicted from the contact geometry and have also remained variable in the "simple_FE" and "simple_FE_HLA" models. Contact parameters in position 2 influence valve vibrations during the closing phase of the valve stroke and when the cam rolls on its basic circle. The stiffness of the finger follower has been found to be a variable with great influence on the entire profile of valve acceleration. Although the default value had been determined from FEM analysis, the calculations have showed that it should be lower. Contact parameters in position 2 and the follower stiffness remain as variables in other models. Acceleration is one of the most important criteria to evaluate the valve train dynamic performance. The computed acceleration, see Figure 8 a), does not match the measured acceleration mainly in the negative part where the coil-to-coil contacts dominate. In principle, the "simple" model has not captured inter-coil contacts as this property is described in section 2 .

\subsection{VALIDATION OF "SIMPLE_FE" MODEL}

The "simple_FE" model has been used mainly for simulating the behavior of the spring coils. (position 13 in Figure 2 b.). The spring 


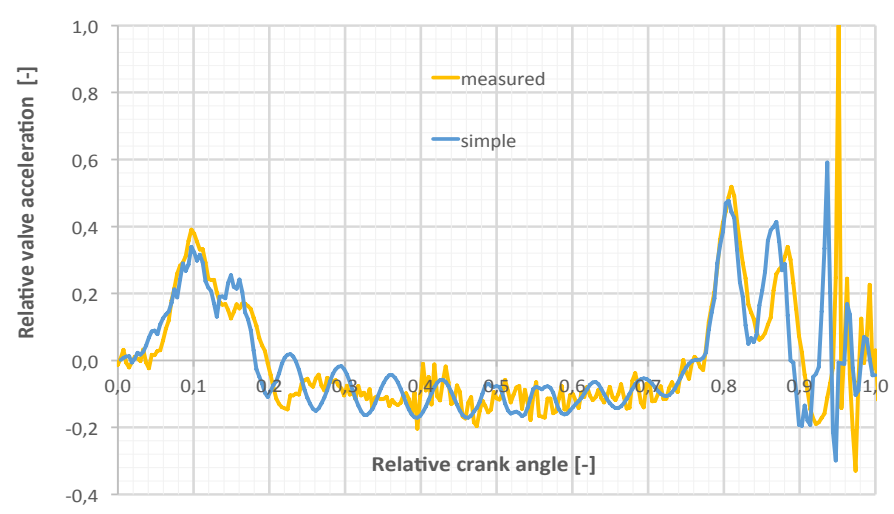

a)

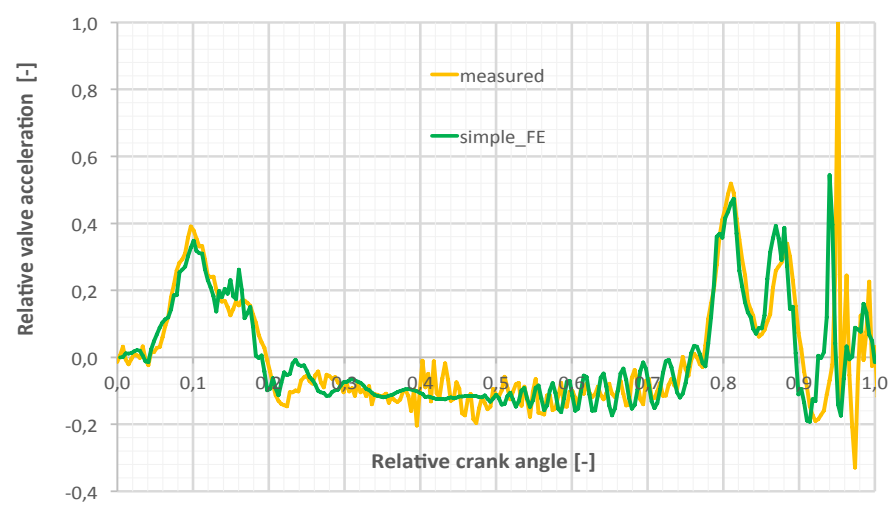

b)

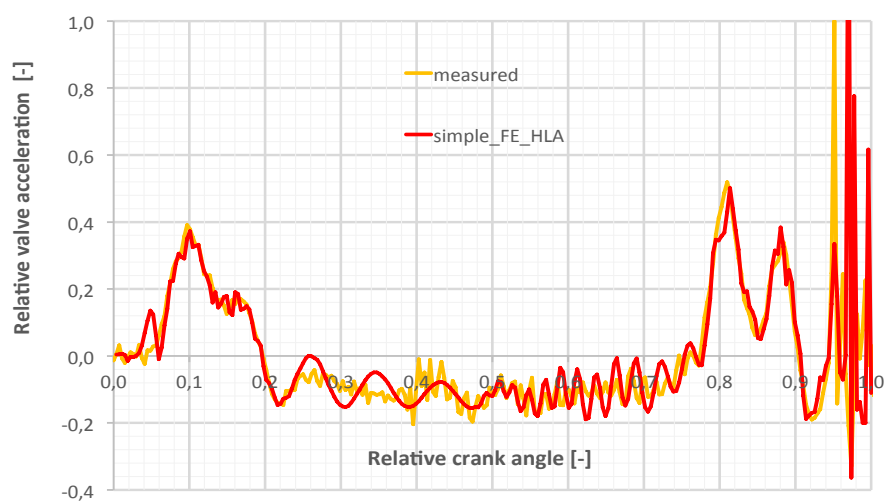

c)

FIGURE 8: Comparison of simulation and measurement on valve acceleration profile: a) "simple" model, b) "simple_FE" model, c) "simple_FE_HLA" model.

OBRÁZEK 8: Porovnání výsledků simulací s měřením na průběhu zrychlení: a) "simple" model, b) "simple_FE" model, c) "simple_FE_HLA" model.

model has main variables as follows: number of elements per coil (NoEpC), number of nodes per coil (NoNpC) and number of clash nodes per element (NoCNpE). Number of clash elements per coil (NoCEpC) is a multiple of NoEpC. The minor variables were contact parameters such as stiffness, damping between coils. The DoE had been calculated with main variables. The best contact fidelity has
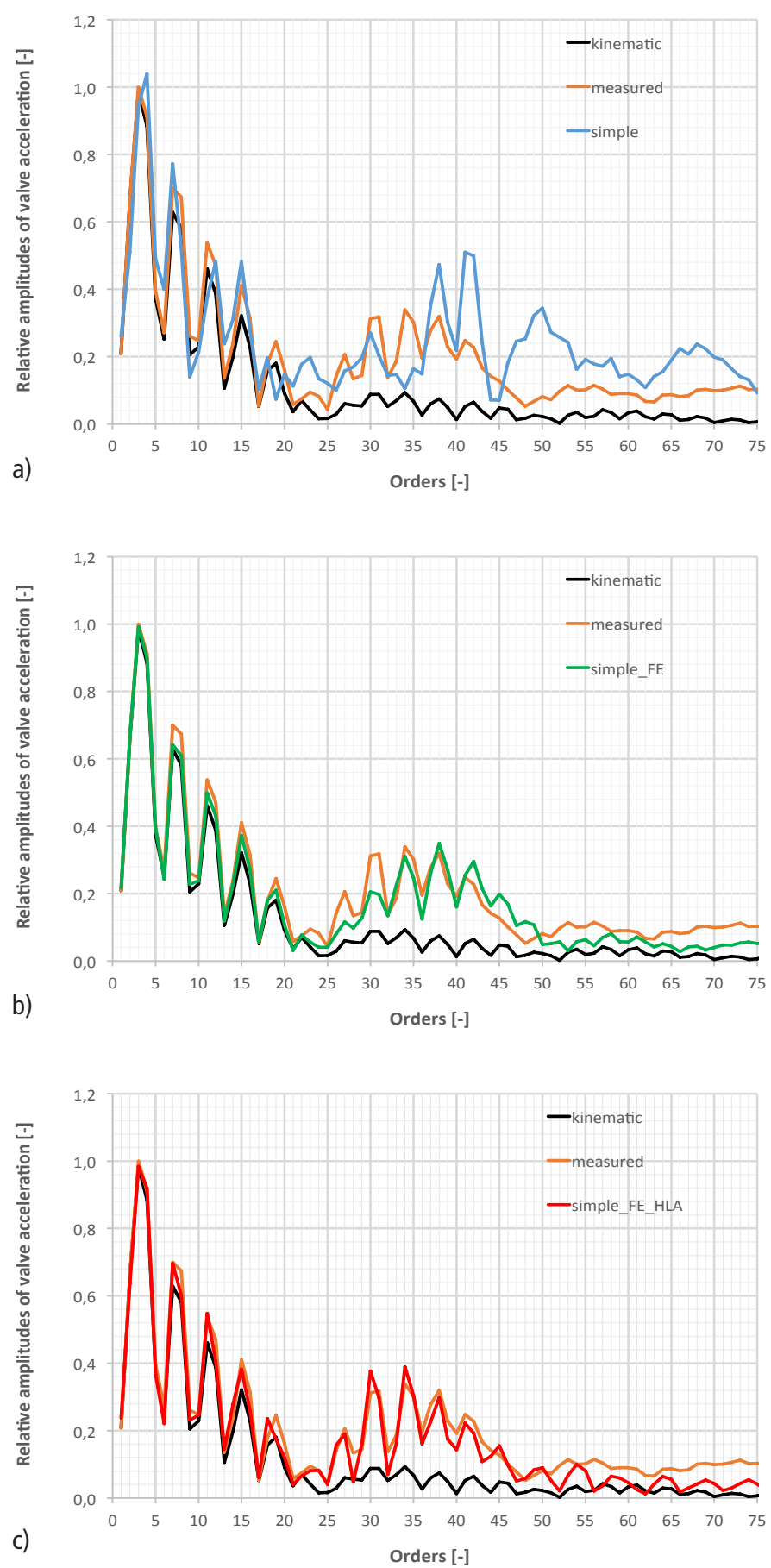

FIGURE 9: Comparison of Fourier order spectra of the valve acceleration profile: a) "simple" model, b) "simple_FE" model, c) "simple_FE_HLA" model.

OBRÁZEK 9: Porovnání amplitud zrychlení ventilu: a) "simple" model, b) "simple_FE" model, c) "simple_FE_HLA" model.

been maintained with a minimum of four clash elements per coil and four elements per coil. The "simple_FE" model has a good overall match with the measured data, see Figure $8 \mathrm{~b}$ ). The contact damping has been found as a parameter of great importance for modeling coils closure during a compression event, if the spring is designed with a progressive rate. Especially the measured profile, 
see the negative part in Figure $8 \mathrm{~b}$ ), shows a significant difference between the opening event, when the follower forces the valve, and the closing event, when the spring closes the valve. Small amplitudes result from reality and the coils are pressed so close to each other that they dampen the mutual surge during the opening event. Damping ceases to act when the coils earn more space during the closing event and their surging closely matches the natural frequencies of the spring. The "simple_FE" model is the best for modeling the events described but it is the most timeconsuming of all.

\subsection{VALIDATION OF "SIMPLE_FE_HLA" MODEL}

The "simple_FE_HLA" model combines the parameter settings found using the "simple" and "simple_FE" models. New variables have been added into the "simple_FE_HLA" model which describe the cylinder volume (position 15 in Figure 2), the leakage path geometry and both plunger spring stiffness and check valve spring stiffness. The high pressure chamber (position 17 in Figure 2) and the clearance between the plunger and cylinder are important for achieving the correct leakage rates. Figure $8 \mathrm{c}$ ) shows that optimization of HLA parameters has given the best fit of positive acceleration peaks with measured data.

Figure 9 shows the comparison of Fourier order spectra for the kinematic acceleration of the first 75 orders with computed and measured acceleration. The computed order spectra closely match the kinematic one up to 25 orders, but with deviations, then the valve train vibrations amplify the amplitudes of higher orders. Mainly the oscillations during the negative acceleration phase are vibrations at the system's natural frequencies in the spectrum from 25 up to 45 mainly due to the spring coils contacts. The "simple" model has not captured this fact, see Figure 9 a), for known reasons, and the model has the worst match with the measured spectrum. On the other hand, the "simple_FE_HLA" model has showed the best fit to the measured spectrum, see Figure $9 \mathrm{c}$ ), even if there is an overshoot at the beginning of the valve opening event and the vibration has higher amplitudes during the first half of negative acceleration, see Figure $8 \mathrm{c}$ ), caused by a reduced number of clash elements per coil compared to the "simple_FE" model.

\section{CONCLUSION}

The aim of the article was to present the DASY base tool for the design of ICE Mechanisms closely focused on the OHC Valve Train. The calibrated and validated "simple_FE_HLA" model has been chosen as a basis for the presented tool, in which a new cam design has being realized. It is the best compromise from the point of view of computational time ("simple" -
$15 \mathrm{sec} .$, "simple_FE" - 30 min., "simple_FE_HLA" - 3 min.). This fact brings more effectivity into the process of cam shape optimization, see Figure 1. The set of variables found for this model remains stored in DASY and most of them have been used for cam shape optimization in the new valve train with geometric changes.

\section{ACKNOWLEDGEMENTS}

This work was supported by:

- Technological Agency, Czech Republic, programme Centre of Competence, project \#TE01020020 Josef Božek Competence Centre for Automotive Industry.

- EU Regional Development Fund in OP R\&D for Innovations (OP VaVpl) and Ministry of Education, Czech Republic, project \#CZ.1.05/2.1.00/03.0125 Acquisition of Technology for Vehicle Center of Sustainable Mobility.

- The Ministry of Education, Youth and Sports program NPU I (LO), project \# L01311 Development of Vehicle Centre of Sustainable Mobility.

\section{LIST OF NOTATIONS AND ABBREVIATIONS}

ICE Internal Combustion Engine

IC Internal Combustion

DASY Design Assistance System

OHC Over Head Camshaft

FFT Fast Fourier Transformation

RPM Revolution Per Minute

DoE Design of Experiment

VT-DESIGN Valve Train Design

GT-SUITE Gamma Technologies Suite

2D, 3D Two, Three Dimensions

FE Finite Elements

FEM Finite Element Method

HLA Hydraulic Lash Adjuster

EHD Elasto Hydrodynamic

\section{REFERENCES}

[1] Tichanek R., Bogomolov S. (2013). Design Assistance System Applications for Simulation of IC Engine Dynamics, In: Journal of Middle European Construction and Design of Cars, Vol. 11, No. 3, pp. 9-15. ISSN 1214-0821

[2] G-TISE Help, GT-SUITE version 7.4. Gamma Technologies Inc., 2014 